EXTENDED REPORT

\title{
Autologous peripheral retinal pigment epithelium translocation in patients with subfoveal neovascular membranes
}

\author{
J C van Meurs, E ter Averst, L J Hofland, P M van Hagen, C M Mooy, G S Baarsma, R W Kuiipers, \\ T Boks, P Stalmans
}

Br J Ophthalmol 2004;88:110-113

See end of article for
authors' affiliations
$\ldots \ldots \ldots \ldots \ldots \ldots \ldots . . . . .$.
Correspondence to:
Jan C van Meurs, MD, The
Rotterdam Eye Hospital,
Schiedamsevest 180,
3011 BH, Rotterdam,
Netherlands;
janvanmeurs@cs.com
Accepted for publication
5 April 2003

....................

\begin{abstract}
Aim: To evaluate the possibility of translocating autologous peripheral retinal pigment epithelial (RPE) cells and enhance their adhesion to improve functional outcome after choroidal neovascular membrane extraction in patients with subfoveal neovascular membranes.

Methods: A prospective, non-controlled surgical study in eight consecutive patients operated between February and July 2001 with final data monitoring in July 2002. All patients had mixed subfoveal membranes of 2-4 disc diameters. Functional tests included Snellen vision and central fixation testing. During vitrectomy, after the extraction of the neovascular complex, $8 \times 10^{4}-16 \times 10^{4}$ RPE cells were removed from the periphery and translocated under the macula following the submacular injection of $2 \mu \mathrm{g}$ of poly-L-lysine to promote adhesion of the cells.

Results: With a follow up ranging from 3 months to 16 months, a pigmented area was seen in the extraction bed of the neovascular membrane in only one patient. Fixation was at the edge of the extraction bed in three patients. Vision remained the same in five patients and deteriorated in three (all with retinal detachment). Retinal detachment due to proliferative vitreoretinopathy occurred in three patients.

Conclusions: The translocation of autologous peripheral RPE cells after membrane extraction was technically possible in a sterile manner, but was associated with a high proliferative vitreoretinopathy rate and in the present series had no measurable positive effect on functional outcome.
\end{abstract}

A ge related macular degeneration (ARMD) is the leading cause of visual loss in Europe and North America in patients aged over 75 , and in the majority of patients legal blindness is due to choroidal neovascularisation. ${ }^{1}$

For small subfoveal neovascular membranes laser coagulation was shown to be better than no treatment 2 years after treatment. ${ }^{2}$ Photodynamic therapy (PDT) has been shown to have better results than controls in patients with a predominantly classic subfoveal membrane. ${ }^{34}$ As there is no evidence based treatment available for large, occult subfoveal neovascularisations, several non-controlled surgical approaches have been reported in such patients. In ARMD malfunction of the retinal pigment epithelium (RPE)-Bruch's membrane-choriocapillaris complex precedes the loss of macular photoreceptors. In its exudative form, visual loss is accelerated by choroidal neovascular invasion of Bruch's membrane, under the RPE and into the subretinal space. Surgical removal of such neovascular membranes in patients with ARMD invariably leads to damage of the RPE, as well as the Bruch's membrane-choriocapillary complex. ${ }^{5-7}$ Spontaneous RPE cell repopulation of the damaged area is ineffective or too late, if at all present. ${ }^{89}$ Nevertheless, a controlled trial is under way which studies simple submacular membrane extraction. ${ }^{10}$

Macular rotation is a conceptually promising approach by creating a fresh undersurface. ${ }^{11}$ A tilted image in successful cases and a high percentage of vision threatening complications because of proliferative vitreoretinopathy (PVR), however, are drawbacks of this technique. ${ }^{12}$

Functioning RPE cells may be trophic for the re-establishment of Bruch's membrane and choriocapillaris. ${ }^{13}{ }^{14}$ Moreover, in animal studies subretinal RPE injection was able to postpone photoreceptor death in RCS rats. ${ }^{15}$
Consequently, other modifications to recreate the underlayer under the macula have included the injection of a homologous fetal cell patch. ${ }^{16}$ Its lack of success was partly attributed to a chronic host versus graft rejection. Recently, Weichel et al reported the lack of functional improvement after the injection of HLA matched homologous RPE cells. ${ }^{17}$

Therefore, several authors used autologous cells: full thickness en bloc translocation of adjacent macular choroid-choriocapillary-Bruch's membrane and $\mathrm{RPE}^{18}$; - translocation by blunt needle aspiration and reinjection of midperipheral RPE cells ${ }^{19}$ - as well as the translocation of IPE cells ${ }^{17}$ For the last two approaches, however, adherence of the injected cells to the damaged Bruch's membrane remains uncertain.

We have chosen to translocate peripheral autologous RPE cells. We further tried to enhance RPE cell adherence by the use of poly-L-lysine. Here we report the results of this approach in a case series of eight patients with a subfoveal neovascular membrane.

\section{Patients and methods}

Patients with a subfoveal choroidal neovascular membrane that was more than 50\% occult on fundus fluorescein angiography (FFA) and larger than 2 disc diameters, with or without submacular blood, were eligible for RPE translocation. Eight patients were included in the study, from 29 January 2001 to 2 July 2001. This study had been approved by the institutional board and written informed consent was obtained from all patients, in accordance with the ethical standards laid down in the 1964 Declaration of Helsinki.

Preoperative examination included history taking, Snellen vision and a dilated pupil fundus examination, including FFA. Postoperative visits were scheduled at 1, 3, and 6 weeks, 
$3,6,9$, and 12 months. The final date of monitoring was 30 July 2002. During each visit Snellen vision testing and a comprehensive examination were performed. At 3, 6, and 12 months fundus pictures were taken and central fixation was tested with the smallest spot $(500 \mu \mathrm{m})$ of the HaagStraat slit lamp.

\section{Preoperative measures}

Three weeks preoperatively argon green laser coagulation retinopexy was performed to wall off the inferior peripheral retina in preparation of the planned peripheral retinectomy. Three hours before surgery, blood was collected from the patient to obtain autologous serum after clotting.

\section{Surgery}

After the induction of a posterior vitreous detachment a complete vitrectomy was performed and a peripheral retinal detachment was created in the walled off inferior retina by the transretinal injection of Ringer's solution into the subretinal space. The detached retina was removed up to the ora serrata with the vitrectome. If the patient was phakic, lensectomy was performed at this stage.

\section{Harvesting and analysis of RPE cells}

We modified a bent 21 gauge aspiration canula by placing a Nylon 8-0 loop on top and connected it to a $10 \mathrm{ml}$ syringe. The RPE cells were gently scraped off Bruch's membrane and aspirated through the canula. We collected $20 \mathrm{ml}$ Ringer/RPE aspirate. The cell aspirate was injected into a closed sterile $30 \mathrm{ml}$ centrifuge tube and autologous serum (10\%) was added to prevent adherence of the cells to the tubing. ${ }^{20}$ After centrifuging ( $3 \mathrm{~g}, 5$ minutes) within a sterile holder the supernatant was aspirated by the surgeon. The cell pellet was resuspended in the remaining drop of supernatant and aspirated in a subretinal canula with a $3 \mathrm{~mm}$ silicone tube transparent extension. The cells remaining in the centrifuge tube were counted in a counting chamber, analysed for viability (morphology by phase contrast microscopy, trypan blue exclusion staining) and seeded into culture discs after the addition of Dulbecco's modified essential medium (DMEM).

Through a paramacular retinotomy the choroidal membrane was removed from the subretinal space with a subretinal forceps.

Poly-L-lysine $(0.2 \mathrm{ml}, 0.1 \mathrm{mg} / \mathrm{ml})$ was injected under the macula through the existing retinotomy. We tried to minimise reflux through the retinotomy by injecting through a third sclerotomy a $1 \mathrm{ml}$ perfluorocarbon (PFCL) bubble over the retinotomy with the injecting canula already inserted under the macula.

After 5 minutes RPE cells were injected subfoveally, again using a PFCL bubble to minimise reflux. Video sequences were made during cell injection, to document proper subretinal injection.

Either a $15 \%$ mixture of $\mathrm{C}_{3} \mathrm{~F}_{8}$ gas or a silicone oil tamponade was used and additional laser applied at the peripheral retinectomy site. In gas filled eyes, an iris claw fixated IOL was inserted; in silicone filled eyes an IOL was inserted at the second surgery when we removed silicone oil. The patient was instructed to remain supine as much as possible during the first 24 hours.

Reoperations were performed for retinal detachments or the removal of silicone oil with secondary intraocular lens implantation.

\section{RESULTS}

Seven patients had ARMD in both eyes, with a fibrovascular scar in the fellow eye in five patients (table 1). One 37 year old woman had a subfoveal membrane secondary to presumed ocular histoplasmosis syndrome (POHS).

The preoperative duration of visual loss in the operated eye ranged from 8 weeks to 6 months. Visual acuity of the operated eye ranged from counting fingers (CF) at 1 metre to 6/120.

Preoperative FFAs were obtained in all patients. Membrane size ranged from 2-4 disc diameters. Subretinal blood was present in six patients.

The number of cells analysed per patients varied from $12.5 \times 10^{3}$ to $70 \times 10^{3}$. Trypan blue exclusion staining revealed that over $90 \%$ of cells were viable.

The heavily pigmented cells we plated adhered to the dish for 5-28 days. Only the cells of patient 4 grew to confluence, with a hexagonal pattern characteristic for RPE cells.

\section{Preoperative course}

Subretinal cell injection appeared successful in all patients (also on reviewing the video recordings) except for patient 2 where possible reflux was noticed during cell injection, although at the time we thought this could have been simulated by subretinal blood egressing.

Silicone oil was used as a tamponade in one patient (patient 3), in whom the preoperatively applied laser barrier proved to be ineffective to prevent retinal detachment from the retinectomy site during surgery; a 15\% C3F8/air mixture was used in the other seven patients (table 1).

\section{Postoperative course}

Retinal detachment developed due to proliferative vitreoretinopathy (PVR) in three patients, who underwent a second vitrectomy with silicone oil tamponade.

Follow up of patients 1 and 3 was only 3 months, because both died. In the other six patients, minimal follow up was 12 months (range 12-16 months). Snellen visual acuity at 3, 6,9 , or 12 months did not show a two line improvement in any patient. In patients 2 and 7 visual loss was clearly caused by the retinal detachment and PVR. These two patients, as well as patient 4 , did subjectively worse. Patients 3, 6, and 8 reported some subjective improvement.

Only in patient 8 was a pigmented area noted under the retina within the membranectomy site. A slight increase in pigmentation was noted during 12 months of follow up; the area of atrophy of choriocapillaris remained unchanged.

Fixation at the edge of the extraction bed of the neovascular membrane was noticed in patients 5, 6, and 8 , but not over the pigmented area in patient 8 .

In patient 4 (37 year old with POHS) a recurrent submacular haemorrhage was observed ophthalmoscopically after 13 months. No signs of infection were observed in any of the patients.

\section{DISCUSSION}

For patients with large, occult subfoveal membranes with or without subretinal blood present, there is no evidence based treatment available. We have translocated autologous peripheral RPE cells to try and improve both the reported autologous $\mathrm{RPE}^{19}$ and $\mathrm{IPE}^{20}$ injection approaches: the latter by choosing RPE cells that may be more likely to take over macular RPE functions than IPE cells ${ }^{212}$; the former by harvesting cells in a manner that would allow us both to collect a greater number of cells and examine these cells for viability in each patient. As to the site of harvesting RPE we chose the inferior retina to minimise the handicap of the resulting scotoma. The disadvantage of having an inferior retinectomy (while the tamponades used had their major effect in the superior half of the retina) was partly overcome by having a formed laser retinopexy at the time of surgery. 
Table 1 Patient characteristics and treatment

\begin{tabular}{|c|c|c|c|c|c|c|c|c|c|c|c|}
\hline Patient & Sex & Age & Preop VA & $\begin{array}{l}\text { No tested } \\
\text { RPE cells }\end{array}$ & Tamponade & Final VA & $\begin{array}{l}\text { Fixation within } \\
\text { extraction bed }\end{array}$ & $\begin{array}{l}\text { Follow up } \\
\text { (months) }\end{array}$ & Reoperations & PVR & Subjective \\
\hline 1 & M & 88 & $6 / 120$ & 15000 & $\mathrm{C}_{3} \mathrm{~F}_{8}$ & $6 / 120$ & not tested & 3 & - & & Same \\
\hline 2 & M & 92 & $6 / 120$ & 7500 & $\mathrm{C}_{3} \mathrm{~F}_{8}$ & $\mathrm{CF}$ & no & 16 & Vitrectomy, sO & yes & Worse \\
\hline 3 & M & 76 & $6 / 120$ & 40000 & $\mathrm{SO}$ & $6 / 120$ & not tested & 3 & - & & Better \\
\hline 4 & $F$ & 37 & CF & 7500 & $\mathrm{C}_{3} \mathrm{~F}_{8}$ & CF3 & no & 14 & - & & Same \\
\hline 5 & M & 76 & CF & 15000 & $\mathrm{C}_{3} \mathrm{~F}_{8}$ & $6 / 120$ & edge & 14 & Vitrectomy, SO & yes & Same \\
\hline 6 & $\mathrm{~F}$ & 72 & $6 / 120$ & 77500 & $\mathrm{C}_{3} \mathrm{~F}_{8}$ & $6 / 120$ & edge & 13 & - & & Better \\
\hline 7 & $M$ & 79 & $6 / 120$ & 40000 & $\mathrm{C}_{3} \mathrm{~F}_{8}$ & $\mathrm{HM}$ & no & 13 & Vitrectomy, so & yes & Worse \\
\hline 8 & M & 67 & $6 / 120$ & - & $\mathrm{C}_{3} \mathrm{~F}_{8}$ & $6 / 120$ & edge & 12 & - & & Better \\
\hline
\end{tabular}

$\mathrm{VA}=$ visual acuity, $\mathrm{CF}=$ counting fingers, $\mathrm{CF} 3=$ counting fingers at 3 metres, $\mathrm{HM}=$ hand motions, $\mathrm{PVR}=$ proliferative vitreoretinopathy, SO $=$ silicone oil.

We aspirated a fairly large number of cells which we showed in a parallel study to be able to survive the aspiration-centrifuge-injection treatment. On cytospin preparation these cells showed RPE specific staining with cytokeratin 8/18 monoclonal antibodies (van Meurs et al, ARVO abstract 2002, no 683). In that study, however, RPE cells from patients with ARMD (although viable as evaluated by trypan blue exclusion) were unable to grow to confluence.

The number of cells we analysed per patient for quality control varied from $12.5 \times 10^{3}$ to $70 \times 10^{3}$, but this number of analysed cells was only a small portion of the number of cells actually reinjected. As the average size of the denuded area after the extraction of the choroidal membrane was approximately 4 disc areas with an estimated cell number of $7 \times 10^{4}$ RPE cells, ${ }^{23}$ the transplanted number of RPE cells would be sufficient if not excessive to repopulate the damaged submacular area.

Adhesion of loose clumps of cells to the damaged Bruch's membrane is important for their survival ${ }^{24}$ and is likely to be a problem for the cells we and others have injected ${ }^{14}{ }^{19}{ }^{20}$; it is not clear how many of the injected cells managed to settle and function metabolically and elaborate substances to reestablish Bruch's membrane and modulate choriocapillary growth. We chose to enhance adhesion by the application of a well known laboratory and graft ${ }^{25}$ adhesion promotor poly-Llysine. We showed in rabbits that poly-L-lysine in the dose used was not retinotoxic (Stalmans et al, EVER abstract, Las Palmas 2000). ${ }^{26}$ It was uncertain, however, whether the injection of poly-L-lysine had any influence on the adhesion of the injected RPE cells in our patients.

Several factors may have contributed to the high incidence of PVR in this study: (1) The creation of a large retinectomy with aspiration of RPE cells caused a blood-retina barrier breakdown. (2) Our technique to try and prevent reflux through the injection site (sealing with PFCL) was probably not successful: we speculate that at least some RPE cells injected under macula may have flowed back through the injection site into the vitreous cavity and contributed to the development of PVR. (3) The same reflux may have occurred with poly-L-lysine, which may have enhanced the adherence of RPE cells to the retina, thereby accelerating PVR. (4) By selecting an inferior rather than a superior retinectomy site while using lighter than water tamponades, the retinectomy was brought into contact with the aqueous phase containing inflammatory cells and RPE cells. ${ }^{27}$

The transplantation of autologous cell sheets would decrease the reflux problem and might increase the chance of RPE cells survival, ${ }^{162829}$ but growth on a sheet and a second operation are challenging in terms of sterility, the choice of the sheet material used, and the surgical placement technique.

Signs of a recurrent choroidal membrane were detected ophthalmoscopically in one patient. As we did not perform fluorescein angiograms to exclude recurrent membranes and our follow up was relatively short (12-18 months), we may be underestimating the rate of recurrence.

Disappointingly, translocated RPE cells were ophthalmoscopically not detectable in seven patients. Several factors may have played a part: reflux to the vitreous cavity preoperatively or postoperatively, because the retinotomy site was not adequately closed and adhesion of the RPE cells to an underlayer never occurred; a rapid clearance of the RPE cells by an inflammmatory reponse secondary to the mechanical removal of the subretinal membrane; loss of pigment due to RPE cell proliferation: non-pigmented RPE cells. Indeed, the pigmentation noted in patient 8 may not be related to the translocated cells, but may merely be a reaction to surgical extraction. ${ }^{8}$ Functionally, vision stabilised in five patients; fixation was on the edge of the extraction bed in three patients, but not over the pigmented area in the only patient with visible pigmentation. In three patients their decrease of vision was caused by retinal detachment.

In conclusion, although we were able to translocate RPE cells in a sterile manner, our findings do not support our assumption that the translocated RPE cells would improve on the functional results of simple membrane extraction. Because of the modest results we obtained in the patients without complications, as well as the severe complications we encountered in others, we have stopped this approach until we have learned more about means to promote the survival of transplanted RPE cells under the macula.

\section{Authors' affiliations}

J C van Meurs, G S Baarsma, The Rotterdam Eye Hospital, Schiedamsevest 180, 3011 BH, Rotterdam, Netherlands

E ter Averst, L J Hofland, Department of Immunology, Erasmus Medical Center, $3011 \mathrm{BH}$, Rotterdam, Netherlands

P M van Hagen, Department of Internal Medicine, Erasmus Medical Center, $3011 \mathrm{BH}$, Rotterdam, Netherlands

C M Mooy, Department of Pathology, Erasmus Medical Center, 3011 $\mathrm{BH}$, Rotterdam, Netherlands

R W Kuijpers, Department of Ophthalmology, Erasmus Medical Center, $3011 \mathrm{BH}$, Rotterdam, Netherlands

T Boks, Sterilization Unit, Erasmus University Medical Center, 3011 BH, Rotterdam, Netherlands

P Stalmans, Department of Ophthalmology, University Hospital, Leuven, Belgium

\section{REFERENCES}

1 Klaver CC, Assink JJ, van Leeuwen R, et al. Incidence and progression rates of age-related maculopathy: the Rotterdam Study. Invest Ophthalmol Vis Sci 2001;42:2237-41.

2 Macular Photocoagulation Study Group. Laser photocoagulation of subfoveal neovascular lesions in age-related macular degeneration. Results of a randomized clinical trial. Arch Ophthalmol 1991;109:1220-31.

3 Bressler NM. Photodynamic therapy of subfoveal choroidal neovascularization in age-related macular degeneration with verteporfin: twoyear results of 2 randomized clinical trials-tap report 2. Arch Ophthalmol 2001;119:198-207.

4 Bressler NM. Verteporfin therapy of subfoveal choroidal neovascularization in age-related macular degeneration: two-year results of a randomized clinical trial including lesions with occult with no classic choroidal neovascularization- 
verteporfin in photodynamic therapy report 2. Am J Ophthalmol 2002; 133:168-9

5 Lafaut BA, Bartz-Schmidt KU, Vanden Broecke C, et al. Clinicopathological correlation in exudative age related macular degeneration: histological differentiation between classic and occult choroidal neovascularisation. Br J Ophthalmol 2000;84:239-43.

6 Lafaut BA. Clinicopathologic correlation of surgically removed submacular tissue. Bull Soc Belge Ophtalmol 2000:49-53.

7 Thomas MA, Dickinson JD, Melberg NS, et al. Visual results after surgical removal of subfoveal choroidal neovascular membranes. Ophthalmology 1994; 101:1384-96

8 Abe T, Yoshida M, Kano T, et al. Visual function after removal of subretinal neovascular membranes in patients with age-related macular degeneration. Graefes Arch Clin Exp Ophthalmol 2001;239:927-36.

9 Sawa M, Kamei $M$, Ohii $M$, et al. Changes in fluorescein angiogram early after surgical removal of choroidal neovascularization in age-related macular degeneration. Graefes Arch Clin Exp Ophthalmol 2002;240:12-6.

10 Bressler NM, Hawkins BS, Sternberg P, et al. Are the submacular surgery trials still relevant in an era of photodynamic therapy? Ophthalmology 2001;108:435-6

11 Machemer R, Steinhorst UH. Retinal separation, retinotomy, and macular relocation: II. A surgical approach for age-related macular degeneration? Graefes Arch Clin Exp Ophthalmol 1993;231:635-41.

12 Eckardt C, Eckardt U, Conrad HG. Macular rotation with and without counterrotation of the globe in patients with age-related macular degeneration. Graefes Arch Clin Exp Ophthalmol 1999;237:313-25.

13 Blaauwgeers HG, Holtkamp GM, Rutten $\mathrm{H}$, et al. Polarized vascular endothelial growth factor secretion by human retinal pigment epithelium and localization of vascular endothelial growth factor receptors on the inner choriocapillaris. Evidence for a trophic paracrine relation. Am J Pathol 1999; 155:421-8.

14 Korte GE, Gerszberg T, Pua F, et al. Choriocapillaris atrophy after experimental destruction of the retinal pigment epithelium in the rat. A study in thin sections and vascular casts. Acta Anat (Basel) 1986;127:171-5.

15 LaVail MM, Li L, Turner JE, et al. Retinal pigment epithelial cell transplantation in RCS rats: normal metabolism in rescued photoreceptors. Exp Eye Res 1992:55:555-62.

16 Algvere PV, Berglin L, Gouras P, et al. Transplantation of RPE in age-related macular degeneration: observations in disciform lesions and dry RPE atrophy. Graefes Arch Clin Exp Ophthalmol 1997;235:149-58.
17 Weichel J, Valtink M, Engelmann K, et al. Use of an oil-hydraulic microinjection pump for subretinal infusions. Ophthalmic Surg Lasers 2002;33:340-2.

18 Stanga PE, Kychenthal A, Fitzke FW, et al. Retinal pigment epithelium translocation after choroidal neovascular membrane removal in age-related macular degeneration. Ophthalmology 2002;109:1492-8.

19 Binder S, Stolba U, Krebs I, et al. Transplantation of autologous retinal pigment epithelium in eyes with foveal neovascularization resulting from agerelated macular degeneration: a pilot study. Am J Ophthalmol 2002;133:215-25

20 Lappas A, Weinberger AW, Foerster AM, et al. Iris pigment epithelial cell translocation in exudative age-related macular degeneration. A pilot study in patients. Graefes Arch Clin Exp Ophthalmol 2000;238:631-41.

21 Thumann G, Bartz-Schmidt KU, Heimann K, et al. Phagocytosis of rod outer segments by human iris pigment epithelial cells in vitro. Graefes Arch Clin Exp Ophthalmol 1998;236:753-7

22 Dintelmann TS, Heimann K, Kayatz P, et al. Comparative study of ROS degradation by IPE and RPE cells in vitro. Graefes Arch Clin Exp Ophthalmol 1999;237:830-9

23 Marmor MF. Structure, function and disease of the retinal pigment epithelium. In: Marmor MF, Wolfensberger TJ, eds. The retinal pigment epithelium. New York: Oxford University Press, 2003:3-9.

24 Tezel TH, Del Priore LV. Reattachment to a substrate prevents apoptosis of human retinal pigment epithelium. Graefes Arch Clin Exp Ophthalmol 1997;235:41-7.

25 Sittinger M, Bujia J, Minuth WW, et al. Engineering of cartilage tissue using bioresorbable polymer carriers in perfusion culture. Biomaterials 1994;15:451-6.

26 Stalmans P, Louage D, Van Ginderdeuren R, et al. Poly-L-lysine subretinally injected does not induce toxic effects to the neuroretina or retinal pigment epithelial (RPE) cells in rabbits. Ophthalmic Res 1998;32(suppl 2):140.

27 Kirchhof B, Wong D, Van Meurs J, et al. Use of perfluorohexyloctane as a long-term internal tamponade agent in complicated retinal detachment surgery. Am J Ophthalmol 2002;133:95-101.

28 Algvere PV, Berglin L, Gouras P, et al. Transplantation of fetal retinal pigment epithelium in age-related macular degeneration with subfoveal neovascularization. Graefes Arch Clin Exp Ophthalmol 1994;232:707-16.

29 Sheng $Y$, Gouras $P, \mathrm{Cao} H$, et al. Patch transplants of human fetal retinal pigment epithelium in rabbit and monkey retina. Invest Ophthalmol Vis Sci 1995;36:381-90 